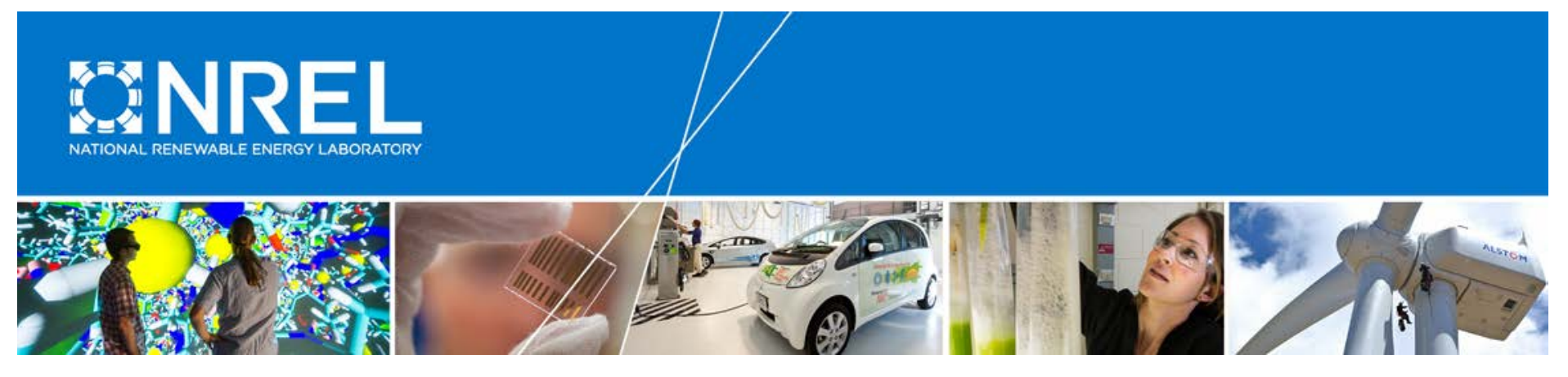

\title{
Evaluating the Value of High Spatial Resolution in National Capacity Expansion Models using ReEDS
}

\section{Preprint}

\author{
Venkat Krishnan and Wesley Cole \\ National Renewable Energy Laboratory
}

Presented at the 2016 IEEE Power \& Energy Society General Meeting

Boston, Massachusetts

July 17-21, 2016

(C) 2016 IEEE. Personal use of this material is permitted. Permission from IEEE must be obtained for all other uses, in any current or future media, including reprinting/republishing this material for advertising or promotional purposes, creating new collective works, for resale or redistribution to servers or lists, or reuse of any copyrighted component of this work in other works.

NREL is a national laboratory of the U.S. Department of Energy Office of Energy Efficiency \& Renewable Energy Operated by the Alliance for Sustainable Energy, LLC

This report is available at no cost from the National Renewable Energy Laboratory (NREL) at www.nrel.gov/publications.

Conference Paper

NREL/CP-6A20-66002

July 2016

Contract No. DE-AC36-08G028308 


\section{NOTICE}

The submitted manuscript has been offered by an employee of the Alliance for Sustainable Energy, LLC (Alliance), a contractor of the US Government under Contract No. DE-AC36-08GO28308. Accordingly, the US Government and Alliance retain a nonexclusive royalty-free license to publish or reproduce the published form of this contribution, or allow others to do so, for US Government purposes.

This report was prepared as an account of work sponsored by an agency of the United States government. Neither the United States government nor any agency thereof, nor any of their employees, makes any warranty, express or implied, or assumes any legal liability or responsibility for the accuracy, completeness, or usefulness of any information, apparatus, product, or process disclosed, or represents that its use would not infringe privately owned rights. Reference herein to any specific commercial product, process, or service by trade name, trademark, manufacturer, or otherwise does not necessarily constitute or imply its endorsement, recommendation, or favoring by the United States government or any agency thereof. The views and opinions of authors expressed herein do not necessarily state or reflect those of the United States government or any agency thereof.

This report is available at no cost from the National Renewable Energy Laboratory (NREL) at www.nrel.gov/publications.

Available electronically at SciTech Connect http:/www.osti.gov/scitech

Available for a processing fee to U.S. Department of Energy and its contractors, in paper, from:

U.S. Department of Energy

Office of Scientific and Technical Information

P.O. Box 62

Oak Ridge, TN 37831-0062

OSTI http://www.osti.gov

Phone: 865.576.8401

Fax: 865.576.5728

Email: reports@osti.gov

Available for sale to the public, in paper, from:

U.S. Department of Commerce

National Technical Information Service

5301 Shawnee Road

Alexandria, VA 22312

NTIS http://www.ntis.gov

Phone: 800.553 .6847 or 703.605 .6000

Fax: 703.605.6900

Email: orders@ntis.gov 


\title{
Evaluating the Value of High Spatial Resolution in National Capacity Expansion Models using ReEDS
}

\author{
Venkat Krishnan, Ph.D., IEEE Member, Venkat.krishnan@nrel.gov, Wesley Cole, Ph.D., Wesley.cole@nrel.gov \\ National Renewable Energy Laboratory, Golden CO 80401, USA
}

\begin{abstract}
Power sector capacity expansion models (CEMs) have a broad range of spatial resolutions. This paper uses the Regional Energy Deployment System (ReEDS) model, a longterm national scale electric sector CEM, to evaluate the value of high spatial resolution for CEMs. ReEDS models the United States with 134 load balancing areas (BAs) and captures the variability in existing generation parameters, future technology costs, performance, and resource availability using very high spatial resolution data, especially for wind and solar modeled at 356 resource regions. In this paper we perform planning studies at three different spatial resolutions-native resolution (134 BAs), state-level, and NERC region level-and evaluate how results change under different levels of spatial aggregation in terms of renewable capacity deployment and location, associated transmission builds, and system costs. The results are used to ascertain the value of high geographically resolved models in terms of their impact on relative competitiveness among renewable energy resources.
\end{abstract}

Index Terms-Capacity Expansion, Electricity System Planning, Optimization, Annual Technology Baseline, Spatial Resolution

\section{NOMENCLATURE}

Sets and indices:

$A$ : Set of all renewable generation technologies

$B$ : Set of all conventional generation technologies

$R$ : Set of variable renewable generation technologies (wind and solar)

$S$ : Set of all generation technologies in A and B and not in R

$y$ : Planning year (2010 to 2050 in steps of two years)

$q$ : Generation technologies (conventional and renewables)

$n$ : Balancing areas (BA), 1 to 134

$i$ : Resource regions, 1 to 356

$k$ : Set denoting region, used for both $n$ and $i$

$s t$ : U.S. states (not including Alaska and Hawaii)

$m$ : Yearly time slices for operations, 1 to 17

Constants and parameters:

$f_{y}(q, n)$ : Financial multipliers - accounts for regional cost factors, technology financing and construction assumptions, and discount rates

$C G(q)$ : Generation technology overnight capital cost in \$/MW

$\operatorname{CGfix}(q)$ : Generation technology fixed operation and maintenance (O\&M) cost in $\$ / M W$-year

$\mathrm{CRF}(\mathrm{q})$ : Generational technology-specific capital recovery factor (CRF)

$\operatorname{Int}(q, i)$ : Renewable generation technology grid interconnection cost in $\$ / M W$
$C T(n, p)$ : Transmission line capital cost in \$/MW

$C G \operatorname{var}(q, n, m)$ : Generation technology variable O\&M cost in $\$ / \mathrm{MWh}$ (includes fuel costs)

$L_{y}(n, m)$ : Energy consumption in MWh at BA $n$ in year $y$ and time slice $m$

$\delta_{y}(n)$ : Yearly energy consumption growth factor at BA $n$

$R P S_{y}(s t):$ State RPS targets in MWh

$T p^{\max }(n, p)$ : Transmission line limit in MW

$B(n, p)$ : Transmission line Susceptance

$C F_{y}(q, n, m)$ : Renewable generation capacity factor in BA

$\phi(q)$ : Generation outage rates

$H(m)$ : Hours in the time slice

$P_{y}^{\max }(q, n)$ : Maximum generation capacity

$P_{y}{ }^{0}(q, n)$ : Existing generation capacity (accounting yearly

retirements)

$C V_{y}(q, n)$ : Capacity value of generation technology

$L_{y}^{p k}(n)$ : Peak load in MW

$\gamma_{y}(n)$ : Reserve margin at BA $n$

Decision variables:

$G_{y}(q, n), G_{y}(q, i)$ : Generation capacity investments in year $y$ in $\mathrm{MW}$

$T_{y}(n, p)$ : Transmission capacity investments in year $y$ in MW

$P_{y}(q, n, m), P_{y}(q, i, m)$ : Energy generated in year $y$ and time slice $m$ in $\mathrm{MWh}$

$T p_{y}(n, p, m)$ : Energy transmitted from BA $n$ to $p$ in year $y$ and time

slice $m$

$\theta(n)$ : Balancing area node angle

\section{INTRODUCTION}

E LECTRITY sector capacity expansion models (CEMs) have long been used to help various electricity sector stakeholders to plan electricity supply and to evaluate the economics and impacts of regulations. For a given set of assumptions about system futures such as technology cost, fuel costs, and load growth, CEMs identify a minimum cost set of generation investments from a range of technologies at appropriate locations and sizes, while satisfying modeled regional policies and other system constraints.

CEMs are often used to optimize the electricity sector over a long planning horizon and a wider geographical region, thereby necessitating highly simplified representations of electricity networks, their spatial resolution, and the generation dispatch process in order to keep the computation tractable. For instance, the U.S. Energy Information Administration's (EIA) National Electricity Modeling System 
(NEMS), a multi-sector planning tool that considers electricity, transportation, residential, commercial, and industrial sectors, aggregates the national electricity sector using 22 supply regions [1]. ICF International's Integrated Planning Model (IPM) [2], a power-sector-only model, includes greater detail with 64 model regions and the associated interregional transmission limits. The National Renewable Energy Laboratory's (NREL) Resource Planning Model (RPM) [3] goes further in terms of its spatial resolution, but considers a smaller region. For example, in its Western Interconnection-wide planning model the system is represented with 34 zonally aggregated nodes, while the $35^{\text {th }}$ zone (focus region) is represented using individual buses, transmission lines, and generators. RPM also models unit commitment and hourly dispatch operations of the generation units in the focus regions over selected dispatch periods in a year, along with DC optimal power flow (DCOPF) models [4] of transmission power flows. Finally, Energy Exemplar's PLEXOS-Integrated Energy Model [5] provides a suite of power system planning tools that allow users to select the appropriate regional (i.e., zonal or nodal) and temporal (yearly operational planning simulation with minute resolution to multi-year investment planning simulation) aggregations, while also allowing explicit gas network modeling for co-optimizing electric-gas systems [6]. The list of tools discussed above is not comprehensive, but provides a sample of the alternative regional aggregations employed in various models intended for electricity sector capacity expansion analysis. Furthermore, each model varies in terms of its emphasis for which it was developed and will have pros and cons with respect to different energy sector planning questions that it is trying to address. The focus of this paper is not to compare these models but to evaluate the value of higher spatial resolution in CEMs especially from the perspective of their impacts on renewable deployments in the long run. For this purpose, this paper uses NREL's Regional Energy Deployment System (ReEDS) model [7].

ReEDS represents the power sector in the contiguous United States with high spatial resolution, dividing the U.S into 356 resource regions and 134 model balancing areas (BAs). Wind and concentrating solar power (CSP) resources are modeled at the resource region level. All other generation technologies, as well as electricity demand and reserves, are modeled at the 134 BAs (shown in Fig. 1). Long-distance transmission is represented between adjacent BAs (also shown in Fig. 1), while ReEDS also models the intra-BA transmission costs required to interconnect wind, $\mathrm{PV}$, and CSP capacity from their resource region to the transmission grid. Capturing the cost, availability, and quality of renewable resources at a high geographical granularity enables ReEDS to find the least cost renewable resource expansions by interconnecting high quality economic resources through appropriate intra-BA and long-distance inter-BA transmission expansions. The focus of this paper is to assess the impact of spatial resolution of renewable resource data on capacity deployments and total planning costs using three levels of spatial representation: 1) native ReEDS resolution (Reference, REF), 2) state-level resolution (STATE), and 3) NERC-level resolution (NERC); and draw appropriate insights on the value of high-resolution renewable energy resource data in capacity expansion models.

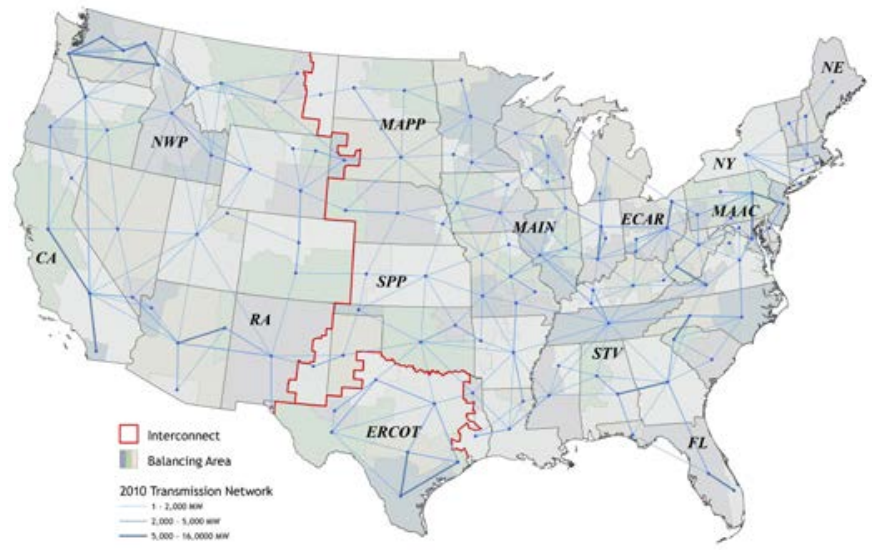

Fig. 1 ReEDS spatial resolution- balancing areas and inter-BA transmission. The figure also shows 13 NERC regions.

Section II provides a description of the ReEDS model. Section III discusses numerical results under the three levels of resource aggregation, and Section IV presents conclusions.

\section{REGIONAL ENERGY DEPLOYMENT SYSTEM (REEDS)}

The ReEDS model has been used for many renewable energy deployment studies, including the SunShot Vision Study [8], the Renewable Electricity Futures Study [9], and the Wind Vision Study [10]. ReEDS has also been used to inform the portfolio of renewable energy integration studies such as Eastern Renewable Generation Integration Study (ERGIS). This section provides a brief overview of ReEDS.

\section{A. Model Formulation}

ReEDS is a linear programming (LP) model that optimizes the expansion and operation of the contiguous United States electricity system in two-year solve periods from 2010 to 2050. Equations (1-10) provide a high-level formulation of the ReEDS LP model for each solve year. Additional details such as operational reserves, renewable resource variability, forecast errors, and curtailment treatments based on statistical estimations, intra-BA spur line (for interconnecting renewables) supply curves, retirements of underutilized generator types, etc. are all not shown. The 2015 Standard Scenarios Annual Report [11] and ReEDS documentation [12] provide a more detailed description of the model structure, assumptions, and scenario results.

Equation (1) is the objective function that minimizes capital investment costs for generation and transmission and generation dispatch costs across all the BAs. ReEDS dispatches all generation using multiple time slices to capture seasonal and diurnal demand and renewable generation profiles. In particular, each of the "solve years" from 2010 through 2050 is divided into 17 time slices (index " $m$ " in equations) that represent four diurnal time slices (morning, 
afternoon, evening, and night) for each of the four seasons (winter, spring, summer, and fall), plus a summer peaking time slice (representing the top 40 hours of summer load). Equation (2) models the nodal energy balance, and eq. (3) enforces state renewable portfolio standards (RPS). ReEDS also models technology set-asides such as wind, solar and distributed generation carve-outs. Equation (4) applies limits on inter-BA transmission flows and eq. (5) models a DCOPF constraint on existing and new $\mathrm{AC}$ line flows. ReEDS assumes the susceptance of the new line to be unchanging in order to render the optimization model linear (or else eq. [5] will be non-linear because line susceptance would also be a decision variable). However, to preserve model fidelity ReEDS updates the line susceptance of the newly invested line in between each solve year. Equations (6-7) model the maximum energy availability from conventional and renewable generation at every time slice in each BA, which is a function of the yearly capacity additions as shown in eq. (8). Equation (9) models the planning reserves constraint to meet the anticipated yearly peak load, where renewable capacities (new and existing) take appropriate capacity values determined using statistical methods and updated between each solve year. Equation (10) constrains the decision variables to be non-negative.

For the year $y \in\{2010,2012, \ldots, 2050)$ :

$$
\begin{aligned}
& \text { Minimize } \sum_{q \in S, n} G_{y}(q, n)\left(f_{y}(q, n) C G(q)\right. \\
& +(\operatorname{CGfix}(q) / C R F(q))) \\
& +\sum_{q \in R, i} G_{y}(q, i)\left(f_{y}(q, i)(C G(q)+\operatorname{Int}(q, i))\right. \\
& +(\operatorname{CGfix}(q) / C R F(q))+\sum_{n, p} T_{y}(n, p) C T(n, p) \\
& +\sum_{q \in B, n, m} P_{y}(q, n, m) \operatorname{CGvar}(q, n, m)
\end{aligned}
$$

$$
\begin{aligned}
& \text { Subject to: } \\
& \qquad \begin{aligned}
\sum_{q \in S} P_{y}(q, n, m)+ & \sum_{q \in R} P_{y}(q, i, m) \\
& =L_{y}(n, m) \delta_{y}(n) \\
& +\sum_{p \neq n} T p_{y}(n, p, m), \quad \forall n, m
\end{aligned}
\end{aligned}
$$

$$
\begin{gathered}
\sum_{q \in A, n \in s t} P_{y}(q, n, m) \geq R P S_{\mathrm{y}}(s t), \quad \forall s t \text { (state) } \\
T p_{y}(n, p, m) \leq T p^{\max }(n, p), \quad \forall n, p, m \\
T p_{y}(n, p, m)=B(n, p)(\theta(n, m)-\theta(p, m)), \\
\forall n, p, m \\
P_{y}(q, n, m) \leq \emptyset(q) P_{y}^{\max }(q, n) H(m), \forall q \in B, n, m \\
P_{y}(q, k, m) \leq C F_{y}(q, k, m) P_{y}^{\max }(q, k) H(m), \\
\forall q \in A, k \in\{n, i\}, m \\
P_{y}^{\max }(q, k)=P_{y}^{0}(q, k)+G_{y}(q, k), \forall q, k \in\{n, i\} \\
\sum_{q \in(A, B)} C V_{y}(q, n) P_{y}^{\max }(q, n) \leq \mathrm{L}_{y}^{p k}(n) \gamma_{y}(n), \forall n \\
G_{y}(q, n), G_{y}(q, i), T_{y}(n, p), P_{y}(q, n, m), P_{y}(q, i, m), \\
T p_{y}(n, p, m), \theta(n, m) \geq 0
\end{gathered}
$$

ReEDS solutions include the amount and location of new and existing generator, storage, and transmission capacity and the resulting generation (at each time slice) provided by the various generators. ReEDS also outputs the total electric sector costs (or net present value of investment and operation), electricity prices, fuel demand and prices, and direct combustion carbon dioxide $\left(\mathrm{CO}_{2}\right)$ emissions.

\section{B. Input assumptions}

ReEDS includes a full suite of major generation and storage technologies, including coal-fired (pulverized coal with and without scrubbers, integrated gasification combined cycle (IGCC) with and without CCS), natural gas-fired (combined cycle and combustion turbine), oil and gas steam, nuclear, biopower (stand-alone and cofiring), wind (landbased and offshore), biopower, geothermal (flash and binary), hydropower (existing small and large hydro, upgrades potentials, non-powered dams, and new stream reach developments), utility-scale solar, CSP, pumped-hydropower storage, compressed-air energy storage, and batteries. All technology cost and performance input assumptions for ReEDS are from NREL's Annual Technology Baseline (ATB) [13]. The ATB is a collection of current and future cost and performance projections for electricity generating units for the U.S. electricity sector.

Annual electric loads and fuel price supply curves are exogenously specified (based on AEO scenarios [14]). ReEDS applies standardized financing assumptions, where all costs, including new capital investments, O\&M costs, fuel costs, and transmission investments, are considered on a 20 year net present value basis. In addition to the general financial assumptions (see the ATB [13] for details), some technology-specific parameters are used within ReEDS, such as technology-specific construction periods, tax credits (existing production and investment tax credit rules) and accelerated tax depreciation rules. ReEDS also accounts for existing air pollution regulations such as California AB32, RGGI, CSAPR, and Clean Power Plan (CPP), although the $\mathrm{CPP}$ is not activated in these scenarios. 


\section{SimUlation ResUlts}

This section presents results for three scenarios: REF, STATE and NERC, each differing in their spatial resolutions of renewable energy resource, cost and performance data. All three scenarios used the ATB mid-case cost and performance assumptions [11]. In the REF scenario, renewable energy is represented at its native resolution in ReEDS (356 regions for wind and CSP, 134 regions for all other technologies). In the STATE scenario, renewable energy costs and capacity factors within each state were assumed to be the capacity-weighted average of costs and capacity factors across all the BAs or resource regions within the state. For the NERC scenario renewable energy costs and capacity factors were averaged across all the BAs or resource regions within each NERC region, resulting in a common cost and capacity factor within each NERC region. In all the scenarios, inter-BA transmission limits and distances were respected.

Figure 2 shows the yearly cumulative capacity from the REF scenario. Under the ATB mid-case assumptions, the portfolio sees substantial growth in renewable energy (hydro, geothermal, biopower, solar, and wind). Renewable energy generation increases from about a $12 \%$ share of national generation in 2010 to about $28 \%$ in $2030,41 \%$ in 2040 , and $54 \%$ in 2050 . Wind contributes about $11 \%, 21 \%$, and $30 \%$ respectively, and solar about $5 \%, 10 \%$, and $15 \%$ respectively.

Comparison of nation-wide generation capacity deployment under the three scenarios revealed appreciable changes primarily in three technologies:

- Utility-scale solar PV capacity decreases with lower resolution.

- Wind capacity increases to compensate for the decrease in PV capacity.

- Gas-CC capacity increases to compensate for PV decrease (additionally, there were some slight changes in gas-CT and storage capacities in some years- driven by varying degrees of variable renewable curtailments).

Table I compares cumulative capacities of PV, wind, and gas-CC, and also the inter-BA and intra-BA transmission across the three scenarios. Numbers in red typeface indicate a decreasing trend, while green typeface indicates an increasing trend. As observed, lower spatial resolution reduces PV deployment. When model inputs, such as PV resources, are aggregated across broader regions, resource sites with low cost and high capacity factors (and capacity value during peak periods) become less attractive as they are averaged with other higher cost, lower performance resources. As a result, these low cost, high performance resources may be "missed" by the model that would otherwise be optimal investments in a highly spatially resolved model. By 2050, we notice PV deployment at the NERC resolution is $\sim 110$ GW less than REF scenario, while the PV mismatch between STATE resolution and REF is $\sim 30 \mathrm{GW}$. Associated with the decrease in PV deployment post-2030, we also notice a decrease in inter-BA $(\sim 2 \mathrm{TW}$-miles or $\sim 1.7 \%)$ and intra-BA $(\sim 1 \mathrm{TW}$-miles or $\sim 33 \%$ ) transmission lines in NERC scenario compared to REF in 2050. The additional capacities are seen to be coming from both wind (also seen by increasing intraBA lines for wind) and gas-CC generation $(\sim 18 \mathrm{GW}$ increase under NERC scenario by 2050). This indicates that in lowresolution models wind resources may seem more attractive (over solar) as a result of averaging the resource supply curves (i.e., averaging the parameters of a remote "good" resource that needs transmission with a local "poor" resource that does not need transmission may improve the "poor" resource's attractiveness as it does not need transmission).

Table II presents the differences in system planning costs in terms of $2015 \$$ (net present value) under the three scenarios. Relative to REF scenario, we observe a $\sim \$ 25 \mathrm{~B}$ and $\sim$ \$50B increase under STATE and NERC resolution. This difference is mainly a result oflower renewable (PV) capital investments and higher fossil fuel costs. Considering the rapidly decreasing PV costs (set to hit $\$ 1 / \mathrm{W}$ SunShot target in 2030s as per the assumptions), if lower resolution CEM models under-invest in low cost PV resources relative to the high resolution models, these CEMS may over estimate total costs as they instead invest in other higher cost resources.

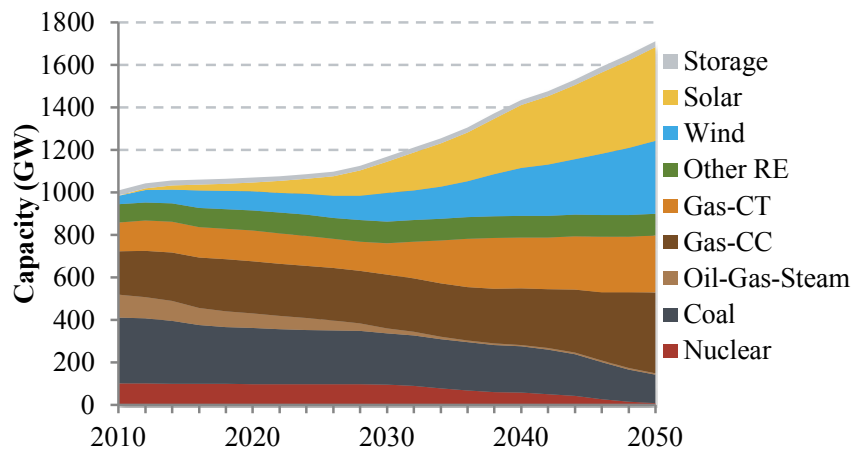

Fig. 2 Cumulative installed capacity - REF scenario

TABLE I COMPARISON OF NATION-WIDE Wind, PV, GAS-CC CUMUlATIVE CAPACITY \& TRANSMisSiON AT DifFERENT SPATIAL AGGREGATION

\begin{tabular}{|c|c|c|c|c|c|c|c|c|c|c|c|c|c|c|c|}
\hline \multirow{2}{*}{$\begin{array}{c}\text { Year } \\
\text { Scenario }\end{array}$} & \multicolumn{3}{|c|}{2010} & \multicolumn{3}{|c|}{2020} & \multicolumn{3}{|c|}{2030} & \multicolumn{3}{|c|}{2040} & \multicolumn{3}{|c|}{2050} \\
\hline & $R E F$ & STATE & NERC & $\boldsymbol{R E F}$ & STATE & NERC & $R E F$ & $S T A T E$ & NERC & $R E F$ & $S T A T E$ & NERC & $R E F$ & STATE & NERC \\
\hline$P V(G W)$ & 0.8 & 0.8 & 0.8 & 21.5 & 21.6 & 22.9 & 77.1 & 70.3 & 52.8 & 186.4 & 167.1 & 95.0 & 300.1 & 268.1 & 190.3 \\
\hline Wind $(G W)$ & 39.7 & 39.7 & 39.7 & 89.7 & 90.5 & 89.1 & 134.7 & 126.2 & 127.6 & 224.9 & 224.4 & 241.8 & 343.2 & 346.0 & 354.8 \\
\hline $\begin{array}{c}\text { Gas-CC }(G W) \\
\text { Inter-BA }\end{array}$ & 204.1 & 204.1 & 204.1 & 245.1 & 245.1 & 245.1 & 253.0 & 255.4 & 252.6 & 265.6 & 268.3 & 268.7 & 380.9 & 383.6 & 397.9 \\
\hline $\begin{array}{c}\text { transmission } \\
\left(10^{3} G W \text {-miles }\right)\end{array}$ & 82.4 & 82.4 & 82.4 & 86.5 & 86.5 & 86.5 & 95.3 & 94.5 & 94.0 & 104.9 & 103.0 & 105.0 & $\begin{array}{c}119.7 \\
(757 \mathrm{GW})\end{array}$ & $\begin{array}{c}118.5 \\
(752 \mathrm{GW})\end{array}$ & $\begin{array}{c}117.7 \\
(749 \mathrm{GW})\end{array}$ \\
\hline $\begin{array}{l}\text { Intra-BA -Solar } \\
\left(10^{6} M W \text {-miles }\right)\end{array}$ & 0.0 & 0.0 & 0.0 & 0.5 & 0.5 & 0.5 & 0.9 & 0.8 & 0.8 & 1.4 & 1.3 & 1.3 & 3.2 & 2.5 & 2.1 \\
\hline $\begin{array}{c}\text { Intra-BA -Wind } \\
\left(10^{6} M W \text {-miles }\right)\end{array}$ & 0.7 & 0.7 & 0.7 & 2.3 & 2.3 & 2.2 & 3.2 & 3.3 & 3.4 & 6.4 & 7.1 & 8.3 & 11.3 & 12.6 & 12.5 \\
\hline
\end{tabular}


Figure 3 presents the regional differences in solar PV cumulative capacity deployments in 2050 at various NERC regions from NERC and STATE scenarios with respect to REF. This shows that aggregation of the cost and performance metrics at the state-level has a relatively limited overall effect on solar PV deployments, while aggregation at the NERC level has a substantial impact, especially in SERC (SC 31GW, VA 18GW), ECAR, CA ( 13 GW), SPP, NWP and ERCOT (TX 14GW).

TABle II COMPARISON OF System PlanNING COSTS (NPV)

\begin{tabular}{c|c|c|c}
\hline Category (2015\$) & $\boldsymbol{R E F}$ & $\boldsymbol{S T A T E}$ & $\boldsymbol{N E R C}$ \\
\hline Conventional Capital & 349.61 & 356.05 & 355.79 \\
Conventional O\&M & 840.02 & 843.66 & 846.05 \\
Conventional Fuel & $\mathbf{2 1 5 9 . 7 8}$ & $\mathbf{2 1 9 0 . 4 0}$ & $\mathbf{2 2 3 4 . 8 3}$ \\
Renewable Capital & $\mathbf{6 1 3 . 6 4}$ & $\mathbf{5 9 8 . 3 8}$ & $\mathbf{5 7 0 . 4 3}$ \\
Renewable O\&M & 238.54 & 236.18 & 237.01 \\
Renewable Fuel & 24.19 & 23.82 & 25.14 \\
Storage Capital & 2.54 & 2.18 & 2.11 \\
Storage O\&M & 9.26 & 9.12 & 9.11 \\
All Transmission & 60.73 & 63.10 & 66.13 \\
Water & 0.02 & 0.02 & 0.02 \\
\hline TOTAL & 4298.33 & 4322.92 & 4346.61 \\
\hline Difference & & $\mathbf{2 4 . 5 9}$ & $\mathbf{4 8 . 2 8}$ \\
\hline
\end{tabular}

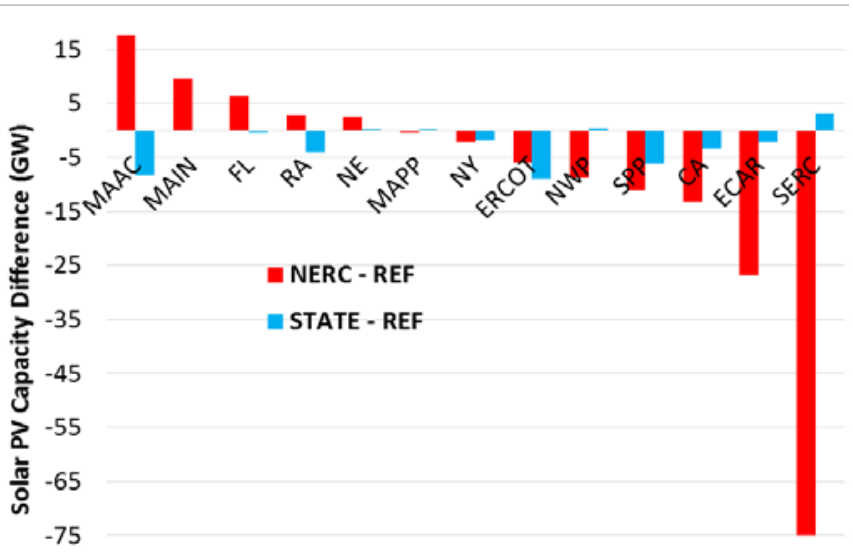

Fig. 3 NERC-region utility-scale solar PV capacity differences at year 2050

Finally, sensitivity to STATE scenario, namely STATE_CP was performed by assuming nearly zero inter-BA transmission distance within each state and approximating the distances across different states as the distance between their geographical centroids. Effectively, this assumption will render the inter-BA transmission within each state (i.e., intrastate in the STATE model) to a copper sheet and will make inter-state transmission access very inexpensive in the STATE model. The results from this simulation indicated an increase in solar PV deployments leading to a difference of about $12 \mathrm{GW}$ in 2050 (performing better than the STATE model). Due to the increase in transmission access (by virtue of making transmission very inexpensive), the low-cost sites, which were otherwise lost due to regional aggregation, could be accessed for deployment (however, additional inter-BA transmission builds are over-estimated to be $\sim 80 \mathrm{GW}$ and hence results from such relaxed models should be taken with appropriate caveats).

\section{CONCLUSIONS}

This paper presented an overview of the ReEDS electricity system capacity expansion model that optimizes the generation portfolio along with transmission expansions from 2010 to 2050 . The model has a high spatial resolution in terms of representing the U.S. electric sector using 134 load balancing areas, with generation technology cost and performance data at the same or higher resolution (356 regions for wind and $\mathrm{PV}$ ). The focus of the paper was on assessing the impact of two degrees of model aggregation by averaging the cost and performance of energy resources at 48 state and 13 NERC region levels.

The ReEDS model results revealed that spatial aggregation of renewable energy resources impacts the competitiveness of renewable resources (which need transmission access). Lower quality resources may appear better when aggregated with higher-quality resources, and vice versa, leading to differences in the relative competitiveness of renewable technologies within the model. This change in competitiveness can lead to suboptimal investment in capacity. The scenarios indicated that solar PV was the most sensitive to the level of aggregation. Higher levels of aggregation led to less PV deployment while wind deployment increased.

\section{REFERENCES}

[1] U.S. Energy Information Administration, "Assumptions to the Annual Energy Outlook 2015- Electricity Market Module," 2015

[2] U.S. Environmental Protection Agency, "Documentation for EPA Base Case v.5.13 Using the Integrated Planning Model," November 2013

[3] C. Barrows, T. Mai, E. Hale, A. Lopez, and K. Eurek, "Considering Renewables in Capacity Expansion Models: Capturing Flexibility with Hourly Dispatch,” IEEE PES General Meeting, Denver, CO, July 2015

[4] A. Liu, Q. Zheng, J. Ho, V. Krishnan, B. Hobbs, M. Shahidehpour, and J. McCalley, Co-optimization of Transmission and Other Supply Resources, NARUC Project No. 3316T5, prepared for the Eastern Interconnection States Planning Council (EISPC), September 1, 2013

[5] PLEXOS Integrated Energy Modelsee http://energyexemplar.com/software/plexos-desktop-edition/

[6] MISO report, "DRAFT Primer for Gas-Electric Modeling in MISO's Phase III Clean Power Plan Study," June 2015

[7] ReEDS model - http://www.nrel.gov/analysis/reeds/

[8] U.S. Department of Energy, "SunShot Vision Study," DOE/GO102012-3037, 2012

[9] T. Mai et al., "Exploration of High-Penetration Renewable Electricity Futures. Vol. 1 of Renewable Electricity Futures Study," NREL/TP6A20-52409-1, 2012

[10] U.S. Department of Energy, "Wind Vision: A New Era for Wind Power in the United States," DOE/GO-102015-4557, 2015

[11] P. Sullivan, W. Cole, N. Blair, E. Lantz, V. Krishnan, T. Mai, D. Mulcahy and G. Porro, "2015 Standard Scenarios Annual Report: U.S. Electric Sector Scenario Exploration," National Renewable Energy Laboratory Technical Report, NREL/TP-6A20-64072, Golden, 2015

[12] W. Short, P. Sullivan, T. Mai, M. Mowers, C. Uriarte, N. Blair, D. Heimiller, and A. Martinez., "Regional Energy Deployment System (ReEDS), NREL/TP-6A20-46534, December 2011

[13] Annual Technology Baseline (ATB) and Standard Scenarios 2015, NREL, http://www.nrel.gov/analysis/data tech baseline.html

[14] Annual Energy Outlook 2015 with projections to 2040, DOE/EIA0383, April 2015, http://www.eia.gov/forecasts/aeo/pdf/0383(2015).pdf 